\title{
Mídias como expansão dos códigos culturais: a história da cultura segundo McLuhan \\ Irene Machado*
}

\section{RESUMO}

Sem mediaçāo tecnológica talvez não houvesse mudanças no modo de pensar. Essa é uma das teses que McLuhan examina em seus estudos sobre as transformações que a tecnologia dos meios de comunicaçāo introduziram na cultura. Enquanto uns acreditavam que vincular o pensamento às ferramentas tecnológicas poderia ser puro delirio, outros conjecturavam: "E se McLuhan estivesse certo?". Os quarenta anos que nos separam dessas inquirições talvez nos dêem aval para arriscar algumas hipóteses. Não para chegar a um veredicto, mas para assuntar a marcha de acontecimentos que criaram uma história: a história das mediações que, através de códigos culturais, subverteram os modos de pensar e de perceber o mundo. Tal é a história secreta da humanidade que McLuhan contou àqueles que, desde a invenção de Gutenberg, desfrutam de dispositivos cognitivos agenciados pela mente da cultura. Um pouco sobre dela falaremos nesse artigo.

\begin{abstract}
Maybe there were no changes int the way of thinking if technological mediation were not implemented among us. That is one of Mcluhan's thesis which is discussed in Mcluhan sludies on media lechnological transformations in culture. While some people believed that the action of joining thought 10 techonogical tools is a nonsense, another one inquired themselves: "If McLuhan were right?". Forty years after these supositions maybe it is time to present some hypotesis. No to reach the truth but to follow the sleps of the history of mediations concerned on the cultural codes that subverted the ways of thinking and perceiving the world. That is the secret history of humanity wich McLuhan told to whom took advantage in using the cognitive device emerged from the mind of culture. That is the history that we will try to present in this paper.
\end{abstract}

Irene Machado Doutora em Letras pela USP; professora do PEPG em Comunicação e Semiócica da PUC.SP $e$ autora, dentre outros, de Escola de Semiótica. A experiencia de Tártu-Moscou para o estudo da Cultura (Ateliê Editorial, 2003). Coordena o Grupo de Pesquisa para o Esiudo dos Espaços Semióticos da Cultura. 


\title{
O professor e o poeta: para além do determinismo tecnológico
}

\author{
O Inusitado
}

\begin{abstract}
Cerca de sete anos. Meu pai começou a me levar para a rondadas matas, a cavalo. Um desfiladeiro. Noite. Envoltos na neblina. Nem via meu pai. Uma vereda estreitissima. Meu pai provavelmente empurrou com a manga um ramo de roseira-brava. O ramo cravou os espinhos em minhas faces. Soltandopequenos gritos, vou tirando os espinhos. De repente, desapareceram a dor e o nevoeiro. Na neblina que se dispersou sob nossos pés, algo mais brilhante que o céu. É a eletricidade. A fábrica de aduelas do príncipe Nakachidze. Depois de ver a eletricidade, deixei completamente de me interessar pela natureza. Objeto não-aperfeiçoado.
\end{abstract}

Um aviador moscovita, meu amigo, me disse: quando ele se precipita nos ares com a velocidade de cem milhões por hora, seu cérebro cinco vezes mais depressa que de costume. $O$ século da máquina vai estimular o pensamento ousado e livre.

Vladimir Maiakóvski (1893-1930)!

As epígrafes que abrem esse artigo mostram, sem dúvida, o deslumbramento que a eletricidade despertou tanto na mente de um poeta, o russo Vladímir Maiakóvski, quanto de um professor de literatura, o canadense Herbert Marshall McLuhan. Para ambos, a eletricidade era o inicio de uma era de mediações capazes de realinhar os processos produtivos materiais e simbólicos.

Conseqüentemente, ambos contavam com a hipótese de que os meios tecnológicos eram capazes de introduzir modificações no próprio modo de perceber o mundo, nele reagir e interagir através da linguagem. Com isso, as idéias do poeta e do professor sobre o mundo elétrico apontam para a possibilidade de se traçar uma outra história da cultura; aquela fundada nos constantes realinhamentos de códigos culturais processadas pelas mediações tecnológicas.

Ainda que para os espíritos apressados envolvimentos como esses sejam responsáveis pela propagação de um determinismo tecnológico ameaçador, para quem tem paciência de acompanhar os desdobramentos das conquistas da tecnologia da comunicação, bem como suas implicações culturais e seus efeitos na mente, não apenas das pessoas, mas da própria cultura, a grande novidade da era elétrica foi a diversificação dos modos de codificar o mundo e de produzir linguagens para além do signo verbal. Os modelos comunicacionais que passam a depender de cabos, circuitos e redes, 
e até mesmo corporal. Contudo, a extensão é um dispositivo de tradução em signos de um ambiente cultural; não significa transposição do órgão sensorial, sequer enquanto representação icônica, ainda que The Medium is the Message tenha explorado algumas possibilidades de híbridos que funcionam como metáforas conceituais ao pensamento em pauta. A metáfora do olho-ouvido traduz a idéia elementar do linguagem elétrica do rádio extensão da voz-e-ouvido - modelizada pela televisão.

Na verdade, a extensão estimula amplificações ambientais criadoras de envolvimento e participação, não envolvimento passivo mas processos ativos que são invisíveis e fundamentais para a compreensão dos meios, suas extensões e a semiose que estimula a percepção para o conhecimento dos signos mobilizadores da cultura. Descortina-se um plano pluralista da experiência humana: um simples ato que envolve a fala não deixa de convocar outros domínios sensoriais. Aquilo que emana da voz pode ser traduzido pelo som, pelos gestos, por expressões moduladas na face, no corpo e no espaço: o meio se torna mensagem. Seu fitho Eric McLuhan e seu parceiro na continuidade de interpretação da obra do pai, Frank Zingrone, convidam a uma reflexão a partir de um exemplo singelo: tente buscar os sentidos provocados por uma frase como "Eu te amo" quando dita pessoalmente, pelo telefone, numa faixa, em cada gênero de uma canção ou de un anúncio. "A resposta recebida terá muito a ver com o meio utilizado" (1998: 20). Isso porque,

a percepção da realidade depende da estrutura da informação. A forma de cada meio está associada com uma disposiçăo ou proporção diferente entre os sentidos que produz novas formas de conhecimento. Tais transformações perceptivas e as novas formas de experimentar criadas pelos meios individuais afetam o usuário independentemente do conteúdo do programa. Isto explica o significado paradoxal de o meio é a mensagem (McLuhan \& Zingrone 1998: 13)

"Disposição", aqui, diz respeito tanto à natureza do meio quanto à capacidade da pessoa para perceber o mundo a partir da codificação proposta por ele. Nos estudos sobre a ecologia da percepção de James Gibson (1979), trata-se de informação disponivel num determinado ambiente. Algo que Gibson examinou em sua teoria das affordances: uma teoria sobre as disponibilidades do ambiente para que haja interação ativa e produtiva entre o percebedor e o seu entorno. Essa disponibilidade dos meios na produção de mensagens pode ser estendida na compreensão dos diferentes efeitos sensoriais que distinguem os meios quentes (que transmitem mais informações e envolvem menos o usuário) e os meios frios (que dão menos informações e permitem ao usuário uma participação sensorial maior). A convocação de uma gama de 
sentidos é evidência de que o modo de comunicação tem um papel decisivo na (re)produção do estado de mente gerador da mensagem. Quanto mais sentidos envolvidos, maior será o espectro do ponto de vista a partir do qual é possível ver e compreender a experiência. "Pois a "mensagem" de qualquer meio ou tecnologia é a mudança de escala, cadência ou padrão que esse meio ou tecnologia introduz nas coisas humanas" (1971: 22). Os ritos tribais em que o corpo e os tambores "falam" tanto quanto a voz (os talked drums da África), o ritual é um "inventário de efeitos" sensoriais em que um meio se rebate no outro criando verdadeiros nichos ecológicos.

Em vez de significado único a mensagem estimula efeitos de sentidos. Entender a gramática de uma manifestação é compreender o meio como mensagem. O meio chama atenção para o modo como os veículos são usados. Estamos falando de sentidos (pluralidade sendorial) e não de sentido (produção de significado por um único sujeito).

Assim como as culturas tribais, a literatura e a mitologia são, igualmente, fontes de muitas das metáforas conceituais de McLuhan em seus estudos sobre a transmutação ecológica dos códigos culturais e suas mediações tecnológicas. $O$ conceito de extensão também lhe foi sugerida pelo mito de Narciso. Para ele,

o mito grego de Narciso está diretamente ligado a um fato da experiência humana, como a própria palavra Narciso indica. Ela vem da palavra grega narcosis, entorpecimento. O jovem Narciso tomou seu próprio reflexo na água por outra pessoa. A extensão de si mesmo pelo espelho embotou suas percepções até que ele se tornou o servomecanismo de sua própria imagem prolongada ou repetida. A ninfa Eco tentou conquistar seu amor por meio de fragmentos de sua própria fala, mas em vão. Ele estava sonado. Havia-se adaptado à extensão de si mesmo e tornara-se um sistema fechado. O que importa neste mito é o fato de que os homens logo se tornam fascinados por qualquer extensão de si mesmos em qualquer material que não seja eles próprios (1971: 59).

A extensão é um prolongamento de outra natureza: a imagem refletida na água não é corpo nem água. É luz e sombra; na verdade, um efeito de sentido. Não se pode esquecer de que o conteúdo de um meio é um outro meio ou sistema disponível na cultura, sendo capaz de traduzi-lo e criar um efeito de sentido. A extensão cria um ambiente de mudanças. Ao ser traduzido em sistema semiótico, o meio se manifesta como ambiente sensorial e nunca como uma mera transposição da matriz corpórea ou sensitiva a partir do qual foi modelizado. A roupa é uma extensão da pele, contudo, não é a pele que 
constitui o sistema semiótico que entendemos como roupa na cultura. Os signos desse sistema são de outra ordem: tecido, traço, desenho, cor, costura, molde, movimento, textura, enfim, temperatura. A extensão enquanto prolongamento é única; contudo, para traduzir a matriz corpórea e sensorial precisa traduzir e criar conexões entre uma diversidade de elementos. Isso é o que entendemos ser o ambiente para McLuhan. Nesse sentido, o ambiente é sempre semiose: nele várias informações são processadas simultaneamente. Prova disso é a metáfora que lhe sugere William Shakespeare como um visionário de meios, até mesmo de alguns jamais cogitados em sua cultura, como a televisão. Em seu livro Os meios de comunicação como extensões do homem (1971: 23) afirma: "Um manual bastante completo para o estudo das extensões do homem poderia ser organizado compilando-se citações de Shakespeare. Não chegariamos a pensar na televisão se alguém nos propusesse, como adivinha, estes versos de Romeu e Julieta?:

"Mas, veja! Que luz é aquela, que passa pela janela? Ela fala-e não diz nada".

Essas duas linhas sugere a McLuhan um meio que iria codificar sinais que seriam traduzidos em informação graças a centenas (ou milhares) de linhas e de pontos de luz (pixel). Como signo, a televisão de Shakespeare seria "uma luz que fala através de uma janela". Que definição poderia suplantar essa metáfora conceitual em apenas duas linhas? Dessa metáfora traduz o próprio conceito de televisão como visão ampliada, estentida, que se alonga não para promover a linearidade, mas para pôr em destaque a diversidade que pode ser alcançada, não através do espelho de Alice, mas através da janela. $O$ efeito de sentido para ser alcançado depende de uma operação tradutória no sistema semiótico que traduz a natureza desse mesmo meio. Quer dizer, implica considerar a alteração: "os meios como extensões de nossos sentidos estabelecem novos índices relacionais não apenas entre os nossos sentidos particulares como também entre si na medida em que se inter-relacionam" (1971: 72). Os meios "jogam" um jogo que está na base do que se considera um híbrido. "O híbrido, ou encontro de dois meios, constitui um momento de de verdade e revelação, do qual nasce a forma nova. Isto porque o paralelo de dois meios nos mantém nas fronteiras entre formas que nos despertam da narcose narcísica. O momento do encontro dos meios é um momento de liberdade e libertação do entorpecimento e do transe que eles impõem aos nossos sentidos" (1971: 75). Do ponto de vista semiótico, a extensão só tem sentido se for considerada no contexto de suas affordances que permitem situar o funcionamento do meio seja em sua condição tecnológica, seja como tradução da informação, seja como codificação em linguagem e na formatação dos produtos em mensagens de circulação no meio social. 
Assim o meio é mensagem porque, dentre outras coisas, é dispositivo - quer dizer - dispõe de mecanismos para gerar informações que podem ou não se tornarem signos. Esse é um pensamento bastante caro para a semiótica da cultura: se a tecnologia gera signos, do ponto de vista da cultura gerenciada pelos meios, a tecnosfera é manancial significativo na constituição da semiosfera - o domínio da semiose, da produção e da interação dos sistemas de signos da cultura.

Tendo em vista que as extensões são sempre ambientais, os meios que operacionalizam a semiose dos códigos culturais passam a ser considerados como lugar privilegiado da sinestesia. Nesse caso, a configuração do ambiente comunicativo implementado pelas tecnologias tem muito mais a ver com o espaço acústico do que com a visualidade. Explicando: "trata-se de um espaço não dotado nem de centro, nem de periferia, diferentemente do espaço estritamente visual, que é extensão e intensificação do olho. O espaço acústico é orgânico e integral, percebido pela interação simultânea de todos os sentidos" (McLuhan \& Zingrone, 1998:284). O ambiente, concebido em sua simultaneidade, não tem nada a ver com a sucessividade e sim com a simultaneidade do tudo-ao-mesmo-tempo-agora. É esse sentido ambiental que me parece o fundamento ecológico da historicidade dos meios como extensão sensorial que, na verdade, mostra 0 prolongamento como movimentos expansivos longe de um fim. Em vez de se pensar em órgãos, trata-se de considerar a expansão do sistema nervoso central capaz de transformar todos os aspectos de nossa vida social e psíquica. Evidentemente o grande problema que esta concepção aciona é o fato de que, quando se fala em extensão do corpo, a referência imediata é, sem dúvida alguma, o homem; contudo, o sistema nervoso central que redireciona os eventos históricos não é a mente do homem, mas a mente da cultura. São as diferentes conexões ambientais que dimensionam o espaço. Dito de outro modo: é o espaço semiótico da cultura que configura o ambiente ecológico com suas expansões nervosas.

Os meios modelizam um sensório em que uma extensão se transmuta em outra. Nesse sentido, McLuhan mostra o quão equivocada é a noção de televisão como extensão do olho. Do ponto de vista da sensorialidade ecológica, televisão, como prevê a etimologia da palavra, é uma visão estendida, ampliada, capaz de abarcar um largo espectro no espaço-tempo. Nessa expansão, este meio é muito mais tátil do que visual: é pelo tato que ela convoca o maior número possível de sentidos. A começar pela baixa definição do vídeo-imagem que faz com que o iconoscópio projete linhas de força em forma de linhas de luz diretamente sobre nossa pele e no ambiente onde a videoimagem circula. Trata-se de uma forma radicalmente diferenciada de alcançar os efeitos que as transformações tecnológicas introduziram na cultura. É por isso que insisto na compreensão da extensão como expansão. 
Graças a esse mecanismo, a cultura é vista como um organismo vivo, provocando mudanças radicais no modo de ver o mundo.

\section{Consideraçōes finais: um ponto de vista extraposto}

A noção de meio como extensão pode ser examinada em suas implicações mais agudas se forem consideradas duas explorações que são fundamentais para se pensar a história das mediações: uma é a noção de ambiente e outra de mente da cultura. Vimos que em Understanding Media, extensão é conceptualizada como prolongamento de órgãos e do próprio corpo.

Tais extensões são uma intensificação, uma amplificação de algum órgão, sentido ou função e, onde quer que aconteça, o sistema nervoso central parece estabelecer um bloqueio autoprotetor da área afetada, isolando-a e anestesiando- $a$ evitando que ela tome consciência do que está ocorrendo" (McLuhan \& Zingrone, 1998: 284).

Por isso, é tão difícil perceber os reais contornos dos novos ambientes tecnológicos que promovendo, na maioria das pessoas, aquilo que McLuhan chamou de "visão do espelho retrovisor" (McLuhan, 1967) que é, na verdade, uma total incapacidade de ver o novo ambiente na dinâmica de sua inovação.

A condição imprescindivel para a visibilidade do novo ambiente se alcança quando a explicitação revela a visão e não o reconhecimento, lembrando aqui o raciocínio dos formalistas russos na conceptualização do efeito de estranhamento. Com isso, os novos ambientes precisam podem ser dimensionados no grande temporalidade da cultura, sem correr o risco de ficar restrito à unicidade do tempo presente e morrer com ele. Isso ć tarefa para uma projeção que não está no presente mas na mente da cultura ambiente dinâmico, invisível, com confluência de pontos de vista. McLuhan formula tal compreensão no contexto da cultura oral-auditiva multiversa, $\mathrm{em}$ comparação com o espaço público criado pela imprensa onde cada indivíduo se desloca tendo pela frente um ponto de vista fixo, individual. Tendo em vista tais espaços, observa que a eletricidade foi capaz de recriar a coletividade em ambiente de massa, deslocando o eixo de visão e envolvimento. Com isso, o olhar fixo num ponto de vista desloca-se para uma mídia comum seja rádio, televisão ou cinema.

Se quisermos entender a ambiência das midias digitais, os sistemas de rede e telemáticas, certamente teremos de ver algo que ainda não está totalmente configurado mas que insinua algumas hipóteses. Evidentemente não se trata de operar nenhum tipo de resgate - nem da visão coletiva, nem do ponto de vista individual no espaço público, nem da visão massificada. 
Estou me referindo ao ponto de vista extraposto em que as conexões em rede e online parecem desenvolver. Trata-se de uma propagação em feixe de focos distintivos. Embora todos estejam conectados ao mesmo tempo, cada um vivencia uma experiência comunicativa radicalmente diferente. No espaço semiótico da cultura de mídias, cada um sintetiza um ponto de vista, ninguém está sozinho, todos se deslocam juntos no mesmo espaço, mas têm autonomia de se cruzarem em direções diferenciadas. Não sei se ainda é muito cedo ou se eu ainda é que não percebi o dimensionamento dessas extraposições. Isso é, contudo, um legado de McLuhan cujas formulações impedem a consolidação de pontos de vista e desafiam cada pesquisador a buscar uma compreensão do ambiente que o envolve. Nesse sentido, Understanding Media continua sendo um ponto de partida para novas explorações sobre a expansão dos códigos na cultura.

Com isso quero dizer que a história das mediações vinculando as descobertas de novos meios com novos modos de pensar não tem nada de profético nem de provocação. Esse é o meu modo de afirmar que McLuhan estava certo e nunca foi acometido de nenhuma forma de delírio.

\title{
Bibliografia
}

GIBSON, James J. The Ecological Approach to Visual Perception. London: Lawrwnce Erlbaum Associates, 1986.

McLUHAN, Eric \& ZINGRONE, Frank (comp.). McLuhan: escritos esenciales (trads. Jorge Basladúa e Elvira Macias). Buenos Aires: Paidós, 1998.

56 McLUHAN, Marshall. A galáxia de Gutenberg: a formação do homem tipográfico (trad. Leônidas G. de Carvalho e Anísio Teixeira). São Paulo: Nacional, 1977. . Os meios de comunicação como extensões do homem (trad. Décio Pignatari). São Paulo: Cultrix, 1971. . Understanding Media. The Extensions of Man. Cambridge: The MTT Press, 1994. McLUHAN, Marshall \& FIORE, Quentin. The Medium is the Massage. An Inventory of Effects. Toronto: Bantan Books, 1967.

SCHNAIDERMAN, Boris. A poética de Maiakóvski através de sua prosa. São Paulo: Perspectiva, 1971.

\section{Notas}

' Os trechos foram retirados de "Autobiografia" (1922-1928) e "De uma entrevista com o escritor norte-americano Michael Gold" (1925) (apud Schnaiderman, 1971: $85-6$ e 134 , respectivamente).

\author{
Palavras-chave \\ 1. Mediação \\ 2. Meios \\ 3. Códigos culturais \\ 4. História \\ 5. Mente
}

